\title{
Catalytic Hydrolysis of Ammonia Borane by Cobalt Nickel Nanoparticles Supported on Reduced Graphene Oxide for Hydrogen Generation
}

\author{
Yuwen Yang, ${ }^{1}$ Fei Zhang, ${ }^{1}$ Hualan Wang, ${ }^{2}$ Qilu Yao, ${ }^{1}$ Xiangshu Chen, ${ }^{1}$ and Zhang-Hui Lu ${ }^{1}$ \\ ${ }^{1}$ College of Chemistry and Chemical Engineering, Jiangxi Normal University, Nanchang 330022, China \\ ${ }^{2}$ Department of Information, Yunnan Institute of Technology and Information, Kunming 650224, China
}

Correspondence should be addressed to Xiangshu Chen; xiangshuchenjx@126.com and Zhang-Hui Lu; luzh@jxnu.edu.cn

Received 19 February 2014; Accepted 11 March 2014; Published 14 April 2014

Academic Editor: Ming-Guo Ma

Copyright (C) 2014 Yuwen Yang et al. This is an open access article distributed under the Creative Commons Attribution License, which permits unrestricted use, distribution, and reproduction in any medium, provided the original work is properly cited.

Well dispersed magnetically recyclable bimetallic CoNi nanoparticles (NPs) supported on the reduced graphene oxide (RGO) were synthesized by one-step in situ coreduction of aqueous solution of cobalt(II) chloride, nickel (II) chloride, and graphite oxide (GO) with ammonia borane $(\mathrm{AB})$ as the reducing agent under ambient condition. The CoNi/RGO NPs exhibits excellent catalytic activity with a total turnover frequency (TOF) value of $19.54 \mathrm{~mol} \mathrm{H}_{2}$ mol catalyst ${ }^{-1} \mathrm{~min}^{-1}$ and a low activation energy value of $39.89 \mathrm{~kJ} \mathrm{~mol}^{-1}$ at room temperature. Additionally, the RGO supported CoNi NPs exhibit much higher catalytic activity than the monometallic and RGO-free CoNi counterparts. Moreover, the as-prepared catalysts exert satisfying durable stability and magnetically recyclability for the hydrolytic dehydrogenation of $\mathrm{AB}$, which make the practical reusing application of the catalysts more convenient. The usage of the low-cost, easy-getting catalyst to realize the production of hydrogen under mild condition gives more confidence for the application of ammonia borane as a hydrogen storage material. Hence, this general method indicates that AB can be used as both a potential hydrogen storage material and an efficient reducing agent, and can be easily extended to facile preparation of other RGO-based metallic systems.

\section{Introduction}

Hydrogen, as a globally accepted clean and environmentally friendly fuel, has attracted widespread research concerns and interests [1]. However, for the widespread use of hydrogen as an energy carrier to achieve sustainable mobility, developing a compact, safe, and affordable means of storing hydrogen remains a major obstacle [2]. Chemical hydrogen storage is thought to be one of the most promising approaches to meet this challenge, because of its considerably high gravimetric and volumetric hydrogen density [3-6]. In recent years, ammonia borane $(\mathrm{AB})$ was discovered as an efficient and safe storage medium for $\mathrm{H}_{2}$ due to the high capacity (19.6 wt.\% and $0.145 \mathrm{~kg} \mathrm{H}_{2} / \mathrm{L}$ ) and stability in ambient atmosphere [7-11]. In the presence of a suitable catalyst, three moles of hydrogen can be released from one mole of $\mathrm{AB}$ at room temperature. The hydrolysis of $\mathrm{AB}$ can be represented as follows [12-14]:

$$
\mathrm{NH}_{3} \mathrm{BH}_{3}(\mathrm{aq})+2 \mathrm{H}_{2} \mathrm{O}(\mathrm{l}) \longrightarrow \mathrm{NH}_{4}\left(\mathrm{BO}_{2}\right)(\mathrm{aq})+3 \mathrm{H}_{2}(\mathrm{~g})
$$

So, the discovery of suitable catalysts becomes the main issue of the practical application of $\mathrm{AB}$ as an on-board hydrogen medium. With the trend of nanocatalysts applied in the hydrolysis of $\mathrm{AB}$ system, transition metal nanoparticles (NPs) catalysts are considered to be a promising option because of their novel structure, electronic properties, and magnetic performances [15-18]. So far, not only nonnoble metal NPs [12,19-24] and noble metal NPs [13, 20, 25-29], but also their composites [14, 30-38] have been tested for hydrolytic dehydrogenation of $\mathrm{AB}$; among them platinum $[20,25,26]$ shows the highest activity. However, concerning 
the element abundance and related economic issues, it is clearly a desired goal to prepare low-cost catalysts with high catalytic activity for the terminal practical application of this reaction system in the fuel cell. The catalytic performance of the metal NPs is highly dependent on the dispersion of the active metals. Thus, the aggregation of metal NPs during the catalytic process due to the high surface energies and magnetic properties is the main impediment to restraint their development [36]. To solve this problem, various surfactants and substrates are successfully utilized to obtain catalysts with preferable dispersity [12-14]. Graphene, a single layer of $\mathrm{sp}^{2}$ carbon lattices, could be an ideal substrate for growing and anchoring metal NPs with good dispersion due to its high specific surface area and large density of free electrons [3739].

In this work, we have discovered that the CoNi/RGO exhibits excellent catalytic activity in hydrolysis of $A B$ for hydrogen generation. Separation of this catalyst from reactant liquid is quite simple by using a magnet, as CoNi/RGO has an excellent magnetic property. This mild and rapid strategy provides great potential for application of ammonia borane as an on-board hydrogen medium.

\section{Experimental}

2.1. Graphite Oxide (GO) Preparation. GO was made by a modified Hummers method [40, 41]. Briefly, natural graphite powder (325 mesh) was placed into an $80^{\circ} \mathrm{C}$ solution of concentrated $\mathrm{H}_{2} \mathrm{SO}_{4}(30 \mathrm{~mL}), \mathrm{K}_{2} \mathrm{~S}_{2} \mathrm{O}_{8}(2.5 \mathrm{~g})$, and $\mathrm{P}_{2} \mathrm{O}_{5}$ $(2.5 \mathrm{~g})$. The mixture was carefully diluted with distilled water and filtered using a 0.2 micron Nylon Millipore filter to remove the residual acid. The product was dried at $80^{\circ} \mathrm{C}$ under ambient condition overnight. The preoxidized graphite was put into cold concentrated $\mathrm{H}_{2} \mathrm{SO}_{4}$, then $\mathrm{KMnO}_{4}$ was added gradually under stirring, and the temperature of the mixture was kept below $20^{\circ} \mathrm{C}$ for $2.5 \mathrm{~h}$. The mixture was stirred at $35^{\circ} \mathrm{C}$ for $4 \mathrm{~h}$. Afterwards, $250 \mathrm{~mL}$ of deionized water was added and the suspension was stirred at $100^{\circ} \mathrm{C}$ for another $2 \mathrm{~h}$. Subsequently, additional $300 \mathrm{~mL}$ of deionized water was added. Shortly after that, $7 \mathrm{~mL}$ of $30 \% \mathrm{H}_{2} \mathrm{O}_{2}$ was added to the mixture to terminate the reaction. The suspension was then repeatedly centrifuged and washed first with $5 \% \mathrm{HCl}$ solution and then with water. Exfoliation of graphite oxide to GO was achieved by ultrasonication of the dispersion for $30 \mathrm{~min}$ [42].

2.2. In Situ Synthesis of RGO Supported CoNi NPs (Co/Ni= 0.5/0.5) and Their Catalytic Activities toward the Hydrolysis of $A B$ (Catalysts $/ A B=0.05$ ). $8 \mathrm{~mL}$ aqueous solution containing $\mathrm{CoCl}_{2}(6.01 \mathrm{mg}), \mathrm{NiCl}_{2}(6.60 \mathrm{mg})$, and $\mathrm{GO}$ solution ( $1.77 \mathrm{~g}$ containing $0.68 \%$ o GO) was kept in a $25 \mathrm{~mL}$ twonecked round-bottom flask. One neck was connected to a gas burette and the other was connected to a pressureequalization funnel to introduce $\mathrm{AB}$ in $2 \mathrm{~mL}$ of aqueous solution containing $34.3 \mathrm{mg} \mathrm{AB}(1 \mathrm{mmol})$. The reactions were started when the aqueous $\mathrm{AB}$ solution was added to the flask with vigorous stirring. The evolution of gas was monitored using the gas burette. After the hydrogen generation reaction was completed, $34.3 \mathrm{mg} \mathrm{AB}(1 \mathrm{mmol})$ was added to the flask and the evolution of gas was monitored. A water bath was used to control the temperature of the reaction solution.

For comparison, RGO supported CoNi NPs with different $\mathrm{Co} / \mathrm{Ni}$ ratio, $\mathrm{GO}$ reduced by $\mathrm{AB}, \mathrm{RGO}$-free $\mathrm{CoNi}$ reduced by $\mathrm{AB}$, and $\mathrm{CoNi} / \mathrm{RGO}$ reduced by $\mathrm{NaBH}_{4}$ were synthesized using the same method.

2.3. Different Supported Carbon Materials. Sets of experiments with different supported carbon materials (such as activated charcoal and graphite powder) were performed at room temperature. All the experiments were performed in the same way as described in Section 2.2.

2.4. Kinetic Studies of Hydrolytic Dehydrogenation of AB Catalyzed by $\mathrm{CoNi} / \mathrm{RGO} N P$ s. Temperature was varied at $25^{\circ} \mathrm{C}$, $30^{\circ} \mathrm{C}, 35^{\circ} \mathrm{C}$, and $40^{\circ} \mathrm{C}$, while the ratio of the concentration of CoNi $(0.05 \mathrm{mmol})$ and $\mathrm{AB}(1 \mathrm{mmol})$ was kept constant at 0.05 to obtain the activation energy $\left(E_{a}\right)$.

2.5. Stability Test. For stability test, catalytic reactions were repeated 5 times by adding other equivalents of $\mathrm{AB}(1 \mathrm{mmol})$ into the mixture after the previous cycle. The molar ratio of catalyst/AB was kept at 0.05 .

2.6. Catalyst Characterization. Transmission electron microscope (TEM), energy-dispersive X-ray spectroscopy (EDS), and selected area electron diffraction (SAED) were observed using FEI Tecnai G20 U-Twin TEM instrument operating at $200 \mathrm{kV}$. Powder X-ray diffraction (XRD) studies were performed on a Rigaku RINT-22005 X-ray diffractometer with a $\mathrm{Cu}_{\mathrm{K} \alpha}$ source $(40 \mathrm{kV}, 20 \mathrm{~mA})$. X-ray photoelectron spectroscopy (XPS) measurement was performed with a Thermo ESCALAB 250XI multifunctional imaging electron spectrometer. FTIR spectra were collected at room temperature by using a Thermo Nicolet 870 instrument using $\mathrm{KBr}$ discs in the $500-4000 \mathrm{~cm}^{-1}$ region. Raman spectrometer was carried out using a confocal Raman microscope (LabRAM HR).

\section{Results and Discussion}

3.1. Synthesis and Characterization. Chemical reduction methods are widely employed for the synthesis of NPs in solution phase in the presence of surfactant [43], whose presence on the surface diminishes the activity to some extent by blocking some of the active sites when NPs are employed as a catalyst [44]. Surfactant-free NPs are difficult to synthesize because growth of in situ generated nuclei cannot be halted. Herein, RGO supported CoNi NPs were successfully synthesized without using any external surfactant. We employed $A B$ itself (much milder than $\mathrm{NaBH}_{4}$ ) as the reducing agent in our reactions.

When $\mathrm{AB}$ was added to the precursor solution containing $\mathrm{CoCl}_{2}$ and $\mathrm{NiCl}_{2}$ at room temperature, reaction started after an induction period of $55 \mathrm{~min}$, while with the precursor solution with graphene oxide (GO), the induction period time decreased to $3.5 \mathrm{~min}$, as shown in Figure S1 (see Figure S1 in Supplementary Materials available online 


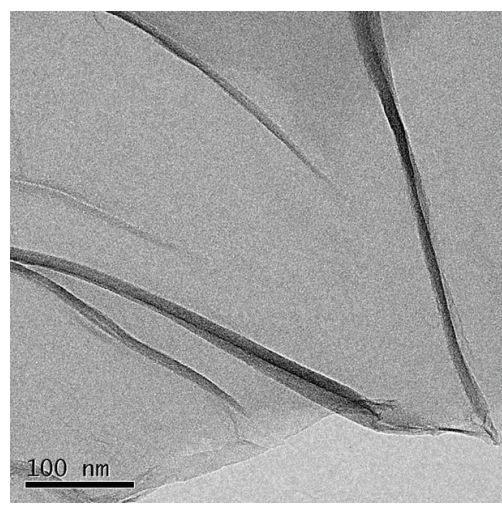

(a)

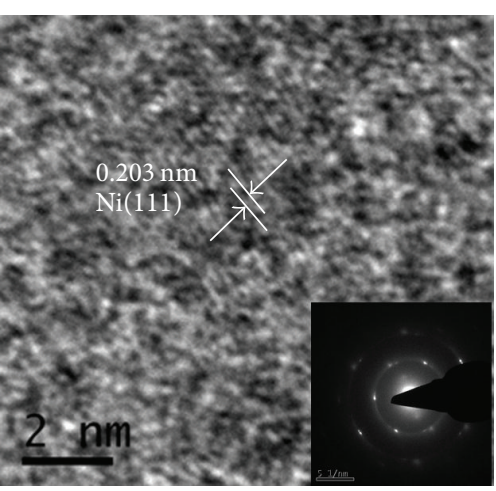

(d)

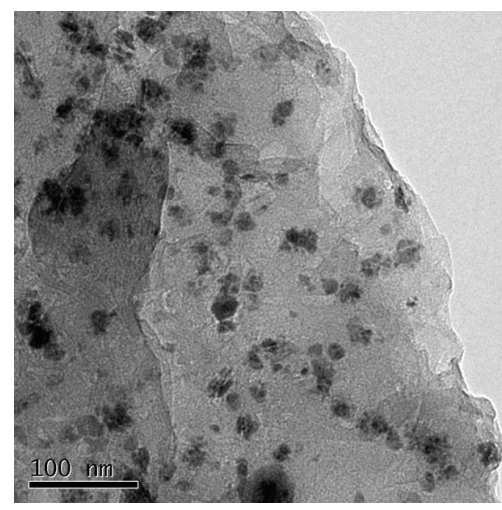

(b)

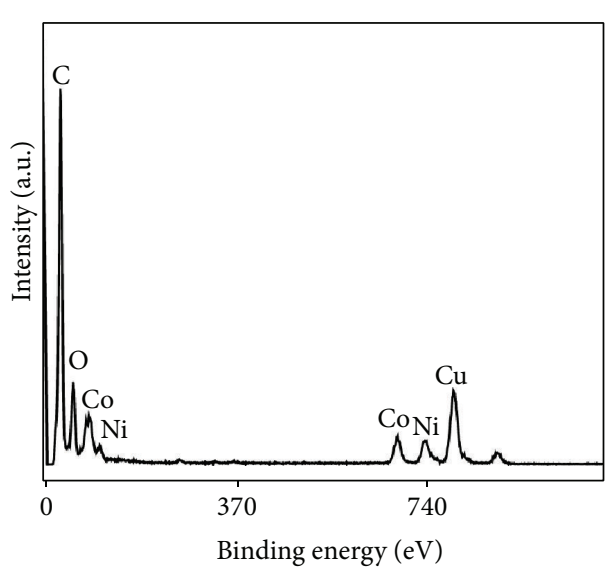

(e)

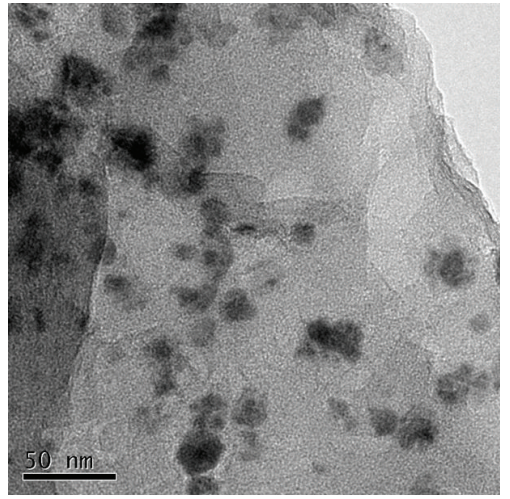

(c)

Figure 1: (a) TEM images of GO sheets and (b) and (c) TEM images of CoNi/RGO, (d) HRTEM image of CoNi/RGO, (d inset) SEAD pattern, and (e) EDS spectrum of CoNi/RGO.

at http://dx.doi.org/10.1155/2014/294350/). The decrease of induction period may result from the cooperative effect between RGO and metal NPs, which is mainly caused by the charge transfer across the graphene-metal interface due to the graphene-metal spacing and Fermi level difference. Just before the onset of $\mathrm{H}_{2}$ evolution, a black colored material was formed. The black powder was RGO supported CoNi NPs (CoNi/RGO).

The microstructures of the $\mathrm{CoNi} / \mathrm{RGO}$ were characterized by transmission electron microscopy (TEM), highresolution TEM (HRTEM), energy-dispersive X-ray spectrometer (EDS), and selective area electron diffraction (SAED) (Figure 1). The GO sheets shown in Figure 1(a) are transparent and corrugated together. As shown in Figures $1(b)$ and $1(c)$, the NPs were well dispersed on RGO, which helps to prevent the agglomeration. A close examination of the catalysts by HRTEM (Figure 1(d)) indicates that the dspacing of the particle lattice is $\sim 0.203 \mathrm{~nm}$, which is consistent with the (111) plane of cubic Ni (JCPDS number 04-0850). The EDS spectrum of the specimen shows the presence of Co and $\mathrm{Ni}$ (Figure 1(e), which was taken from the specially marked area in the TEM image), with the atomic ratio for $\mathrm{Co}: \mathrm{Ni}$ being detected to be $0.02: 0.02$, which is in good agreement with the appointed atomic ratio $(1: 1)$. Therefore, the Co NPs may be in amorphous phase.
Figure $2 \mathrm{~S}$ shows the power XRD pattern of the Co/RGO and $\mathrm{Ni} / \mathrm{RGO}$. The diffraction peak attributed to $\mathrm{Ni}$ (111) is observed. However, no diffraction peak of Co exists, which may be caused by the amorphous phase of Co. Therefore, the peak at around $44.10^{\circ}$ in the power XRD pattern of the as-prepared $\mathrm{CoNi} / \mathrm{RGO}$ (Figure 2) corresponds to the $\mathrm{Ni}$ (111). Furthermore, the most intense peak at around $11.5^{\circ}$ that corresponds to the (001) reflection of GO disappeared and a new peak at around $25.1^{\circ}$ is observed in the as-synthesized RGO supported CoNi NPs, indicating that GO is successfully reduced to RGO.

$\mathrm{CoNi} / \mathrm{RGO}$ was further characterized by X-ray photoelectron spectroscopy (XPS) to investigate the surface nature of the CoNi NPs and RGO (Figure 3). Compared with the peaks of GO (Figure 3(a)), the intensities of oxygen containing functional groups (such as $-\mathrm{C}-\mathrm{O},-\mathrm{C}=\mathrm{O}$, and $\mathrm{COO}$ ) in $\mathrm{Co} / \mathrm{RGO}$ (Figure 3(b)) decrease significantly, which also reveal the reduction of GO to RGO. Figure 3(c) shows the peaks of Co 2p. There are three peaks whose peak tops are 778.6, 781.7, and $786.0 \mathrm{eV}$, which stand for zero valent Co and oxidized Co [45]. Figure 3(d) shows the peaks of Ni 2p. There are two peaks at 853.2 and $870.0 \mathrm{eV}$ which are attributed to zero valent $\mathrm{Ni}$, while the other two peaks at $856.6 \mathrm{eV}$ and $874.0 \mathrm{eV}$ stand for oxidized $\mathrm{Ni}$ [46]. The formation of the 
TABLE 1: Catalytic activity of different catalysts used for the hydrolytic dehydrogenation of AB.

\begin{tabular}{|c|c|c|c|}
\hline Catalyst & TOF $\left(\mathrm{mol} \mathrm{H}_{2} \cdot \mathrm{mol} \mathrm{catalyst}^{-1} \cdot \mathrm{min}^{-1}\right)$ & $E_{a}\left(\mathrm{~kJ} \mathrm{~mol}^{-1}\right)$ & Reference \\
\hline $\mathrm{Ru} / \gamma-\mathrm{Al}_{2} \mathrm{O}_{3}$ & 23.05 & 67 & [27] \\
\hline $\mathrm{CoNi} / \mathrm{RGO}$ & 19.54 & 39.89 & This work \\
\hline Ag@CoNi/graphene & 15.89 & 47 & {$[35]$} \\
\hline Au@Co & 13.64 & - & {$[40]$} \\
\hline $\mathrm{Co}_{0.32} \mathrm{Pt}_{0.68} / \mathrm{C}$ & 10.99 & 41.5 & {$[31]$} \\
\hline Ag@Co/graphene & 10.24 & 20.03 & {$[32]$} \\
\hline PSMA-Ni & 10.1 & 38.12 & {$[21]$} \\
\hline Cu@Co/graphene & 8.36 & 51.3 & {$[22]$} \\
\hline Ag@Ni/graphene & 7.7 & 49.56 & {$[32]$} \\
\hline $\mathrm{Co}_{0.75} \mathrm{~B}_{0.25}$ & 7.24 & 40.85 & {$[23]$} \\
\hline $\mathrm{RGO} / \mathrm{Pd}$ & 6.25 & $51 \pm 1$ & {$[28]$} \\
\hline $\mathrm{Ag} / \mathrm{C} / \mathrm{Ni}$ & 5.32 & 38.91 & {$[33]$} \\
\hline $\mathrm{RuCo} / \gamma-\mathrm{Al}_{2} \mathrm{O}_{3}$ & 3.64 & 47 & {$[34]$} \\
\hline $\mathrm{Ni} / \gamma-\mathrm{Al}_{2} \mathrm{O}_{3}$ & 2.45 & - & {$[20]$} \\
\hline $\mathrm{Co} / \gamma-\mathrm{Al}_{2} \mathrm{O}_{3}$ & 2.27 & 62 & [20] \\
\hline
\end{tabular}

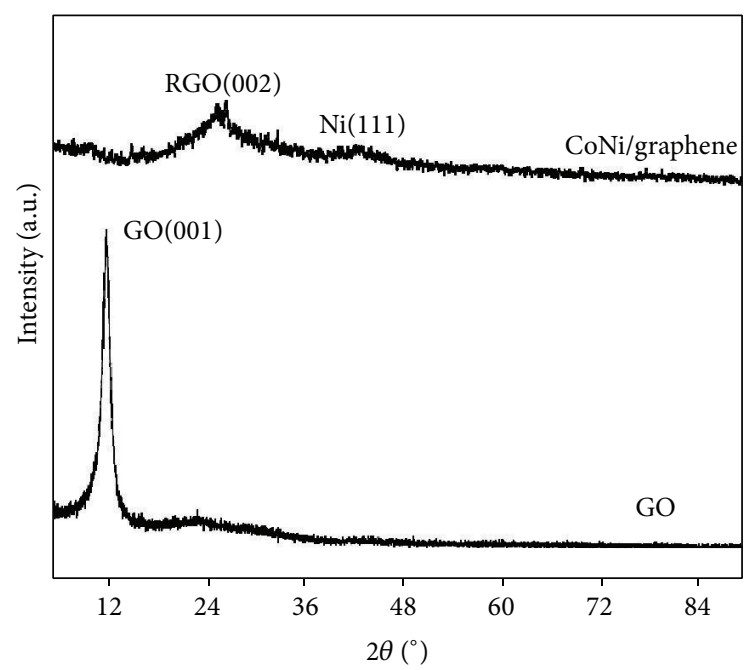

Figure 2: XRD patterns of GO and CoNi/RGO.

oxidized Co and oxidized Ni most likely occurs during the sample preparation process for XPS measurements.

Two peaks centered at 1316 and $1577 \mathrm{~cm}^{-1}$ appear in the Raman spectra of the GO and RGO supported CoNi NPs (Figure 4(a)), corresponding to the $D$ and $G$ bands of the carbon products, respectively. The intensity ratio of the $D$ to $G$ band $\left(I_{D} / I_{G}\right)$ is generally accepted to reflect the degree of graphitization of carbonaceous materials and defect density. After loading of the CoNi NPs, the $I_{D} / I_{G}$ of GO is increased from 1.14 to 1.61 . The relative changes in the $D$ to $G$ peak intensity ratio confirm the reduction of GO during the in situ fabrication. Figure 4(b) displays the FTIR spectra of GO and $\mathrm{CoNi} / \mathrm{RGO}$ NPs. After the formation of RGO supported CoNi NPs, the disappearance of $\mathrm{C}=\mathrm{O}$ peak at $1716 \mathrm{~cm}^{-1}$, C$\mathrm{OH}$ peak at $1399 \mathrm{~cm}^{-1}$, and $\mathrm{C}-\mathrm{O}$ peak at $1064 \mathrm{~cm}^{-1}$ of GO further indicates that the $\mathrm{GO}$ was reduced to RGO during the process.
3.2. Catalytic Activities for Hydrolysis of AB. Figure 5(a) shows the composition effect of RGO supported $\mathrm{Co}_{1-x} \mathrm{Ni}_{x}$ on $\mathrm{AB}$ hydrolysis $(x=\mathrm{Co}: \mathrm{Co}+\mathrm{Ni})$, with the molar ratio for catalysts to $\mathrm{AB}$ being 0.05 . Obviously, by changing the molar ratio, the NPs demonstrate different catalytic activities. As a result, $\mathrm{Co}_{0.5} \mathrm{Ni}_{0.5} / \mathrm{RGO}$ displays the best catalytic performance in the hydrolysis of $\mathrm{AB}$, generating a stoichiometric amount of hydrogen $\left(\mathrm{H}_{2} / \mathrm{AB}=3.0\right)$ in the shortest time $(3.07 \mathrm{~min})$ with a turnover frequency (TOF) value of $19.54 \mathrm{~mol} \mathrm{H}_{2} \mathrm{~mol}$ catalyst ${ }^{-1} \mathrm{~min}^{-1}$, which is higher than the most reported nonnoble metal-based NPs and even many noble metalbased NPs, as shown in Table 1, while CoNi/RGO show better activity than pure Co NPs or pure Ni NPs supported on RGO, indicating the positive effect of metal interaction in the bimetallic CoNi NPs on hydrogen generation from hydrolysis of $A B$. As shown in Figure S3, compared with the NPs reduced by $\mathrm{NaBH}_{4}$, the as-synthesized NPs generated by $\mathrm{AB}$ exhibit higher catalytic activities, which confirms that it is possible to achieve much more control over the nucleation and growth process of the RGO by choosing weaker reducing agents.

Figure 5(b) presents the plots of the volume of hydrogen generated from the $\mathrm{AB}$ solution versus the reaction time at room temperature in the presence of pure $\mathrm{Co}_{0.5} \mathrm{Ni}_{0.5} \mathrm{NPs}, \mathrm{GO}$, and the $\mathrm{Co}_{0.5} \mathrm{Ni}_{0.5} / \mathrm{RGO}$ catalysts. No hydrogen generation was observed for GO, suggesting that GO has no catalytic activity for the hydrolysis of $\mathrm{AB}$. The hydrogen productivity from $\mathrm{AB}$ catalyzed by pure $\mathrm{Co}_{0.5} \mathrm{Ni}_{0.5} \mathrm{NPs}$ is around $49.3 \%$ in $79.7 \mathrm{~min}$. However, the activity of $\mathrm{Co}-\mathrm{Ni} / \mathrm{RGO}$ is much higher than that of pure Co-Ni NPs without RGO. The enhanced catalytic activity for $\mathrm{AB}$ hydrolysis reaction should result from the cooperative effect between RGO and CoNi NPs. Furthermore, to study the effects of the supported carbon materials on the catalytic performances of the assynthesized bimetallic NPs, $\mathrm{Co}_{0.5} \mathrm{Ni}_{0.5}$ /graphite powder and $\mathrm{Co}_{0.5} \mathrm{Ni}_{0.5}$ /activated charcoal are prepared and their catalytic activities toward hydrolysis of $\mathrm{AB}$ are studied. As 


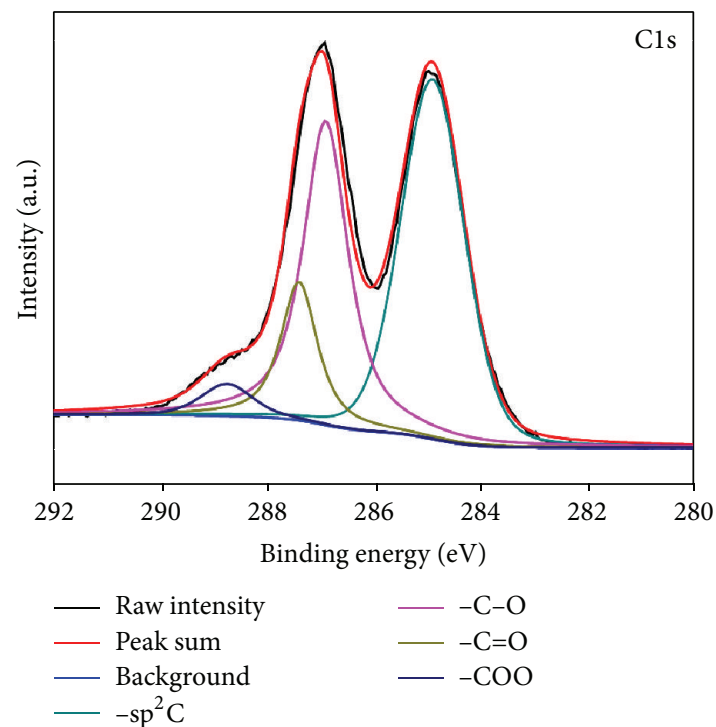

(a)

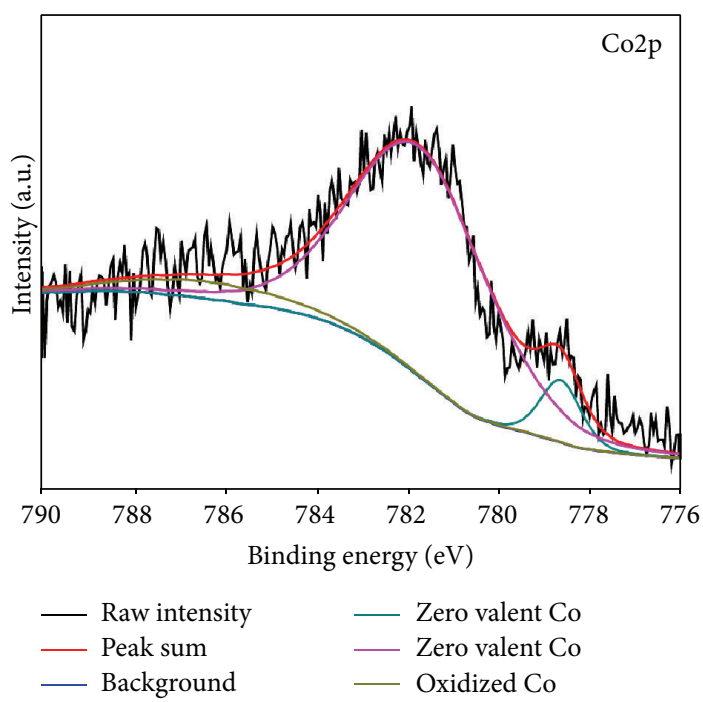

(c)

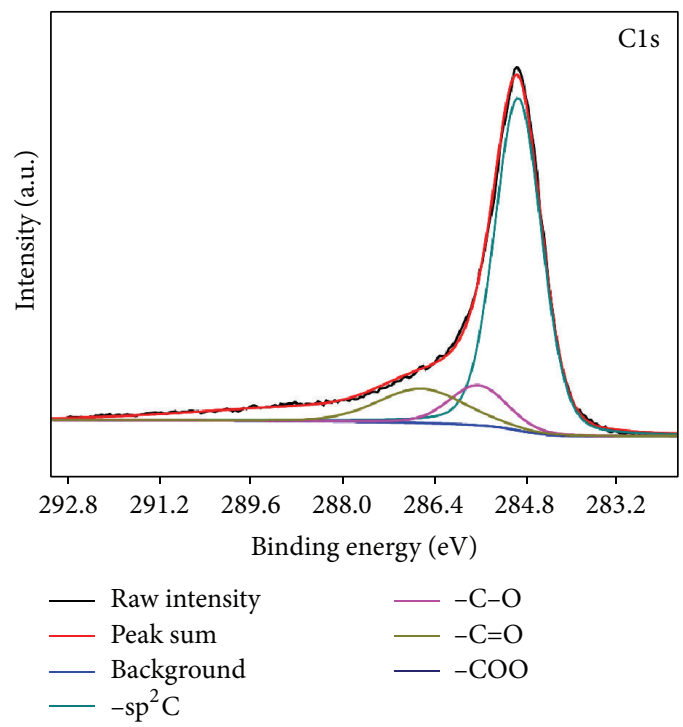

(b)

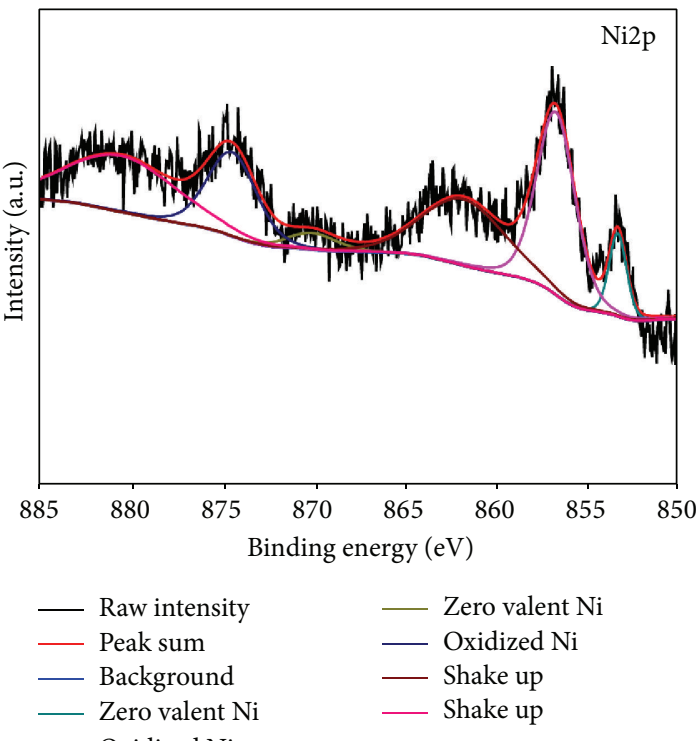

(d)

Figure 3: XPS of spectra of ((a) and (b)) Cls of GO and CoNi/RGO, (c) Co2p of CoNi/RGO, and (d) Ni2p of CoNi/RGO.

shown in Figure S4, their catalytic activities are inferior to that of $\mathrm{Co}_{0.5} \mathrm{Ni}_{0.5} / \mathrm{RGO} \mathrm{NPs}$, highlighting the dominant factor of $\mathrm{RGO}$ in facilitating hydrolysis of $\mathrm{AB}$ in our system.

In order to get the activation energy $\left(E_{a}\right)$ of the $\mathrm{AB}$ hydrolysis catalyzed by CoNi/RGO NPs, the hydrolytic reactions at different temperatures in the range of $298-313 \mathrm{~K}$ were carried out. The values of the rate constant $k$ at different temperatures were calculated from the slope of the linear part of each plot from Figure 6(a). The Arrhenius plot of ln $k$ versus $1 / T$ for the catalyst is plotted in Figure 6(b), from which the apparent activation energy was determined to be approximately $39.89 \mathrm{~kJ} / \mathrm{mol}$, being lower than most of the reported $E_{a}$ values (Table 1), indicating the superior catalytic performance of the as-synthesized CoNi/RGO catalysts.

3.3. Reusability and Recycle Ability. The reusability of the catalysts is crucial in the practical application. The recyclability of $\mathrm{CoNi} / \mathrm{RGO}$ catalysts up to the fifth run for hydrolysis of $\mathrm{AB}$ is shown in Figure 7. The as-synthesized $\mathrm{CoNi} / \mathrm{RGO}$ catalysts retain $68 \%$ of their initial activities in the hydrolysis of $\mathrm{AB}$ in the fifth run, indicating their superior recycle stabilities. The observed activity loss is likely to result from the precipitation of metaborates to the catalyst surface [19]. Moreover, the in situ synthesized CoNi/RGO 


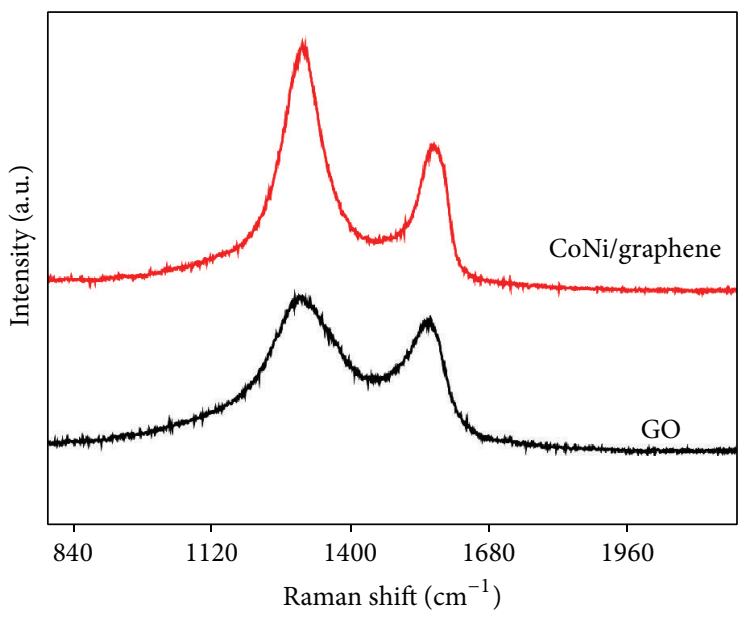

(a)

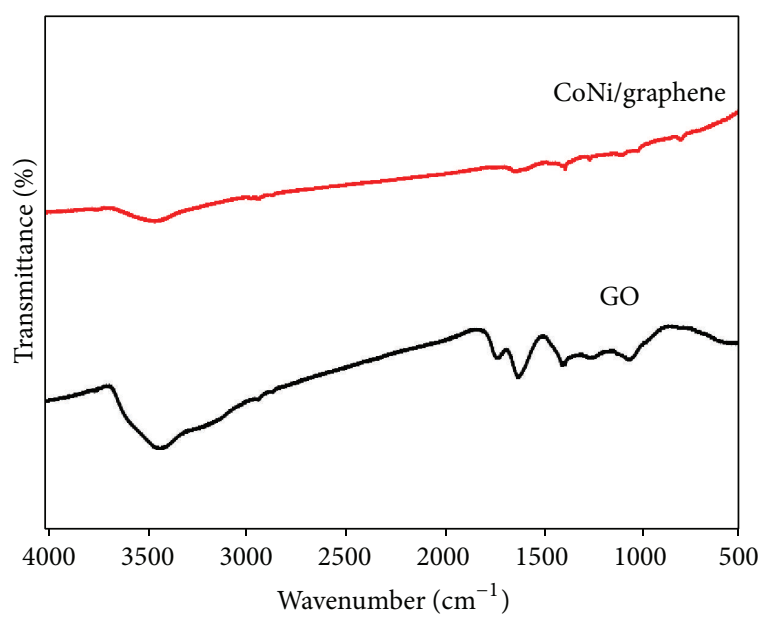

(b)

Figure 4: (a) Raman spectra and (b) FTIR spectra of the GO and CoNi/RGO.

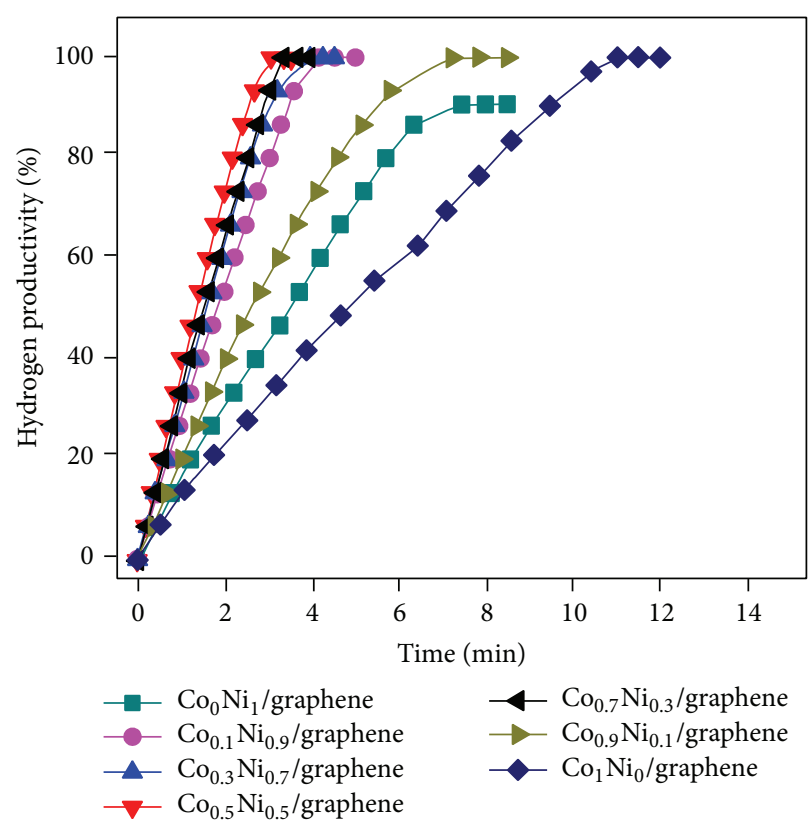

(a)

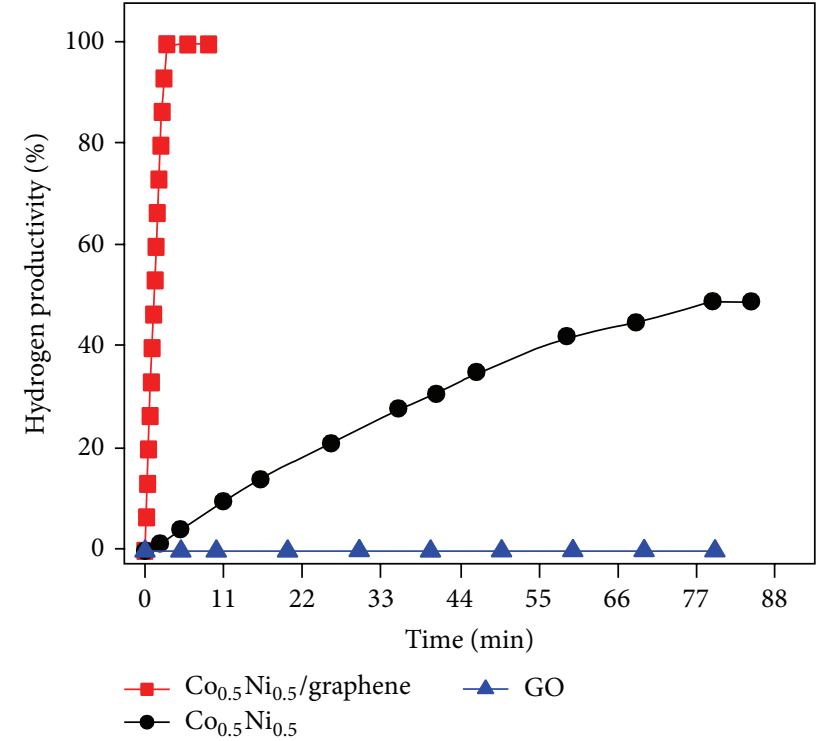

(b)

FIGURE 5: Hydrogen generation from hydrolysis of ammonia borane $(0.10 \mathrm{M}, 10 \mathrm{~mL})$ over (a) the CoNi/RGO catalysts at ambient condition. $\mathrm{CoNi} / \mathrm{AB}=0.05$ (molar ratio) and (b) the $\mathrm{Co}_{0.5} \mathrm{Ni}_{0.5} / \mathrm{RGO}, \mathrm{Co}_{0.5} \mathrm{Ni}_{0.5}$, and GO.

are magnetic and thus can be separated from the reaction solution by an external magnet (Figure 7 inset), which makes the practical recycling application of nanocatalysts more convenient.

\section{Conclusion}

In summary, we have developed a facial in situ one-step method for the synthesis of magnetic RGO supported bimetallic CoNi NPs using $\mathrm{AB}$ as a reductant. The CoNi/RGO exhibit superior catalytic activity, with a turnover frequency (TOF) value of $19.54 \mathrm{H}_{2} \mathrm{~mol}$ catalyst ${ }^{-1} \mathrm{~min}^{-1}$ and an activation energy $\left(E_{a}\right)$ value of $39.89 \mathrm{~kJ} \mathrm{~mol}^{-1}$. The RGO supported CoNi NPs exhibit much higher catalytic activity than the graphite powder and activated charcoal supported or monometallic and RGO-free CoNi counterparts. Compared with catalysts reduced by $\mathrm{NaBH}_{4}$, the $\mathrm{CoNi} / \mathrm{RGO}$ catalysts generated by the milder reducing agent $\mathrm{AB}$ exhibit higher catalytic activities. Moreover, the CoNi/RGO catalysts show good durable stability and magnetic recyclability for the hydrolytic dehydrogenation of $\mathrm{AB}$, which makes the practical recycling application of the catalyst more convenient. This simple synthetic method can be extended to other RGObased bimetallic systems for more application. 


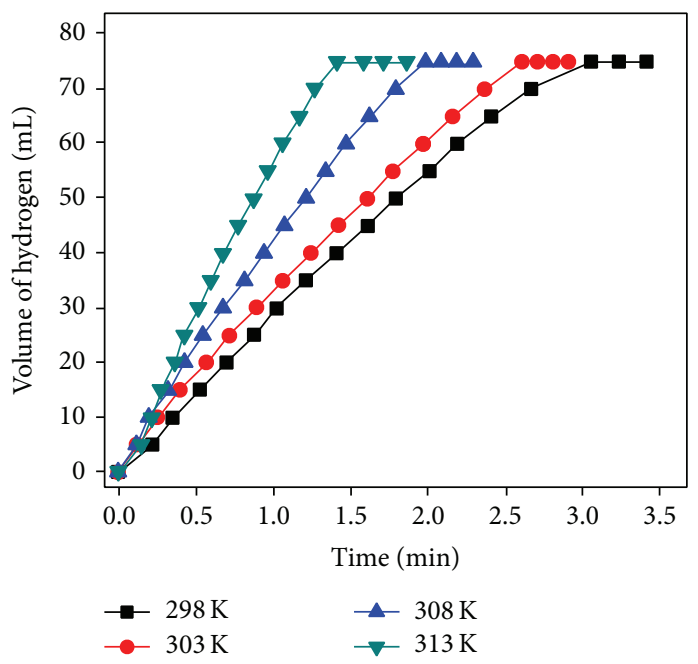

(a)

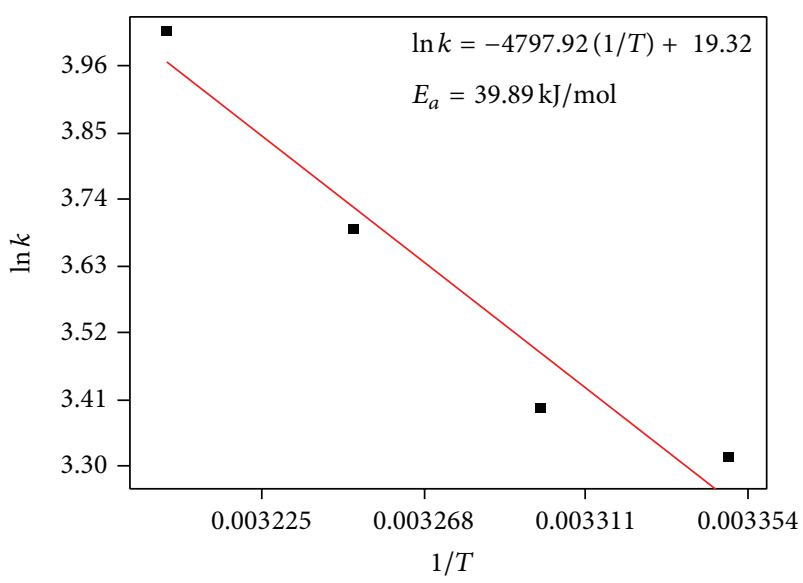

(b)

FIGURE 6: (a) Plots of volume of hydrogen generated versus time for $\mathrm{Co}_{0.5} \mathrm{Ni}_{0.5} / \mathrm{RGO}$ catalyzed hydrolysis of $\mathrm{AB}$ at four different temperatures in the range of $298-313 \mathrm{~K}, \mathrm{CoNi} / \mathrm{AB}=0.05$ and (b) Arrhenius plot obtained from the data of Figure 6(b).

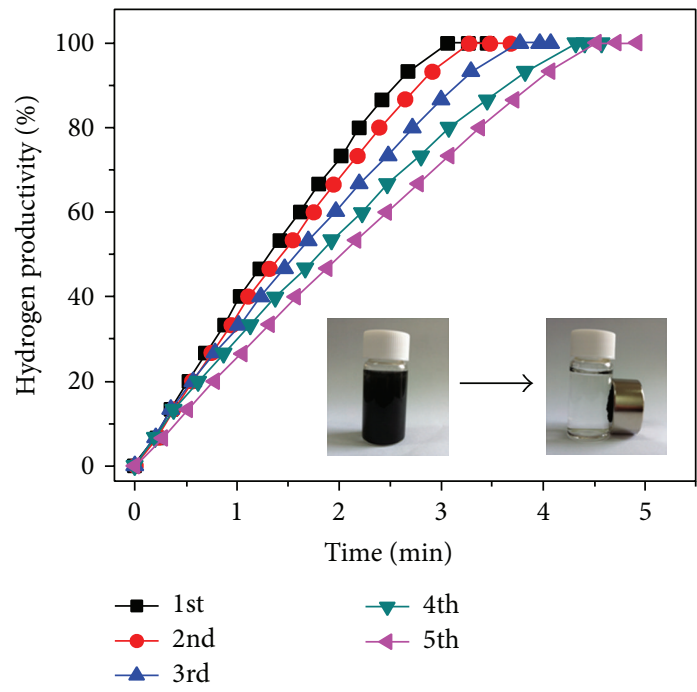

(a)

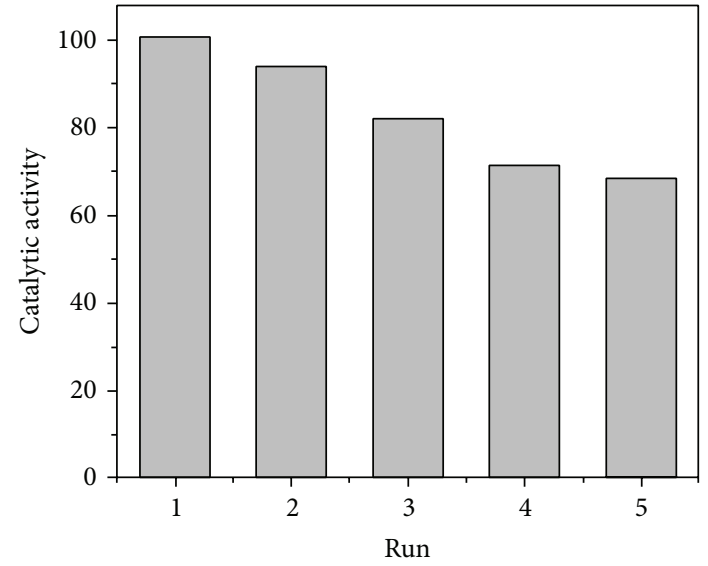

(b)

Figure 7: (a) Hydrogen generation from hydrolysis of ammonia borane $(0.10 \mathrm{M}, 10 \mathrm{~mL})$ catalyzed by $\mathrm{Co}_{0.5} \mathrm{Ni}_{0.5} / \mathrm{RGO}$ from the 1 st to 5 th cycle, $\mathrm{CoNi} / \mathrm{AB}=0.05$, and (inset) photographs of the $\mathrm{Co}_{0.5} \mathrm{Ni}_{0.5} / \mathrm{RGO}$ before (left) and after (right) the magnetic separation; (b) percentage of initial catalytic activity of $\mathrm{Co}_{0.5} \mathrm{Ni}_{0.5} / \mathrm{RGO}$ in successive runs after the reuse for the hydrolysis of $\mathrm{AB}$.

\section{Conflict of Interests}

The authors declare that there is no conflict of interests regarding the publication of this paper.

\section{Acknowledgments}

This work was financially supported by the National Natural Science Foundation of China (no. 21103074), the Natural Science Foundation of Jiangxi Province of China (nos. 20114BAB203010 and 20132BAB203014), Jiangxi Provincial Department of Science and Technology (no. 20111BDH80023), and the Scientific Research Foundation of Graduate School of Jiangxi Province (YC2013-S105). Zhang-Hui Lu was supported by the Sponsored Program for Cultivating Youths of Outstanding Ability in Jiangxi Normal University, the Young Scientist Foundation of Jiangxi Province (20133BCB23011), and “Gan-po talent 555" Project of Jiangxi Province.

\section{References}

[1] L. Schlapbach and A. Züttel, "Hydrogen-storage materials for mobile applications," Nature, vol. 414, no. 6861, pp. 353-358, 2001. 
[2] J. S. Zhang, Y. Zhao, D. L. Akins, and J. W. Lee, "Calorimetric and microscopic studies on the noncatalytic hydrothermolysis of ammonia borane," Industrial \& Engineering Chemistry Research, vol. 50, pp. 10407-10413, 2011.

[3] U. Eberle, M. Felderhoff, and F. Schüth, "Chemical and physical solutions for hydrogen storage," Angewandte Chemie International Edition, vol. 48, pp. 6608-6632, 2009.

[4] J. Yang, A. Sudik, C. Wolverton, and D. J. Siegel, "High capacity hydrogen storage materials: attributes for automotive applications and techniques for materials discovery," Chemical Society Reviews, vol. 39, no. 2, pp. 656-675, 2010.

[5] U. B. Demirci and P. Miele, "Chemical hydrogen storage: "Material" gravimetric capacity versus "system" gravimetric capacity," Energy and Environmental Science, vol. 4, no. 9, pp. 3334-3341, 2011.

[6] Z. H. Lu, Q. L. Yao, Z. J. Zhang, Y. W. Yang, and X. S. Chen, "Nanocatalysts for hydrogen generation from ammonia borane and hydrazine borane," Journal of Nanomaterials, vol. 2014, Article ID 729029, 2014.

[7] Z. H. Lu and Q. Xu, "Recent progress in boron- and nitrogenbased chemical hydrogen storage," Functional Materials Letters, vol. 5, Article ID 1230001, 9 pages, 2012.

[8] C. W. Hamilton, R. T. Baker, A. Staubitz, and I. Manners, "B-N compounds for chemical hydrogen storage," Chemical Society Reviews, vol. 38, no. 1, pp. 279-293, 2009.

[9] M. Yadav and Q. Xu, "Liquid-phase chemical hydrogen storage materials," Energy \& Environmental Science, vol. 5, pp. 96989725, 2012.

[10] H. L. Jiang and Q. Xu, "Catalytic hydrolysis of ammonia borane for chemical hydrogen storage," Catalysis Today, vol. 170, no. 1, pp. 56-63, 2011.

[11] U. B. Demirci and P. Miele, "Sodium borohydride versus ammonia borane, in hydrogen storage and direct fuel cell applications," Energy and Environmental Science, vol. 2, no. 6, pp. 627-637, 2009.

[12] S. Akbayrak and S. Özkar, "Ruthenium(0) nanoparticles supported on multiwalled carbon nanotube as highly active catalyst for hydrogen generation from ammonia-borane," ACS Applied Materials \& Interfaces, vol. 4, pp. 6302-6310, 2012.

[13] J. Wang, Y. L. Qin, X. Liu, and X. B. Zhang, "In situ synthesis of magnetically recyclable graphene-supported Pd@Co core-shell nanoparticles as efficient catalysts for hydrolytic dehydrogenation of ammonia borane," Journal of Materials Chemistry, vol. 22, pp. 12468-12470, 2012.

[14] J. M. Yan, Z. L. Wang, H. L. Wang, and Q. Jiang, "Rapid and energy-efficient synthesis of a graphene-CuCo hybrid as a high performance catalyst," Journal of Materials Chemistry, vol. 22, pp. 10990-10993, 2012.

[15] L. Kesavan, R. Tiruvalam, M. H. A. Rahim et al., "Solvent-free oxidation of primary carbon-hydrogen bonds in toluene using Au-Pd alloy nanoparticles," Science, vol. 331, no. 6014, pp. 195199, 2011.

[16] R. Ghosh Chaudhuri and S. Paria, "Core/shell nanoparticles: classes, properties, synthesis mechanisms, characterization, and applications," Chemical Reviews, vol. 112, no. 4, pp. 2373-2433, 2012.

[17] R. Ferrando, J. Jellinek, and R. L. Johnston, "Nanoalloys: from theory to applications of alloy clusters and nanoparticles," Chemical Reviews, vol. 108, no. 3, pp. 845-910, 2008.

[18] R. C. Sekol, X. K. Li, P. Cohen, G. Doubek, M. Carmo, and A. D. Taylor, "Silver palladium core-shell electrocatalyst supported on MWNTs for ORR in alkaline media," Applied Catalysis B: Environmental, vol. 138-139, pp. 285-293, 2013.

[19] Z. H. Lu, J. P. Li, A. L. Zhu et al., "Catalytic hydrolysis of ammonia borane via magnetically recyclable copper iron nanoparticles for chemical hydrogen storage," International Journal of Hydrogen Energy, vol. 38, pp. 5330-5337, 2013.

[20] Q. Xu and M. Chandra, "Catalytic activities of non-noble metals for hydrogen generation from aqueous ammonia-borane at room temperature," Journal of Power Sources, vol. 163, no. 1, pp. 364-370, 2006.

[21] Ö. Metin and S. Özkar, "Water soluble nickel( 0$)$ and cobalt( $(0)$ nanoclusters stabilized by poly(4-styrenesulfonic acid-comaleic acid): highly active, durable and cost effective catalysts in hydrogen generation from the hydrolysis of ammonia borane," International Journal of Hydrogen Energy, vol. 36, pp. 1424-1432, 2011.

[22] Y. S. Du, N. Cao, L. Yang, W. Luo, and G. Z. Cheng, "One-step synthesis of magnetically recyclable rGO supported $\mathrm{Cu} @ \mathrm{Co}$ core-shell nanoparticles: highly efficient catalysts for hydrolytic dehydrogenation of ammonia borane and methylamine borane," New Journal of Chemistry, vol. 37, pp. 30353042, 2013.

[23] A. K. Figen, "Dehydrogenation characteristics of ammonia borane via boron-based catalysts $(\mathrm{Co}-\mathrm{B}, \mathrm{Ni}-\mathrm{B}, \mathrm{Cu}-\mathrm{B})$ under different hydrolysis conditions," International Journal of Hydrogen Energy, vol. 38, p. 9186, 2013.

[24] Y. W. Yang, Z. H. Lu, Y. J. Hu et al., "Facile in situ synthesis of copper nanoparticles supported on reduced graphene oxide for hydrolytic dehydrogenation of ammonia borane," RSC Advances, vol. 4, pp. 13749-13752, 2014.

[25] M. Chandra and Q. Xu, "Room temperature hydrogen generation from aqueous ammonia-borane using noble metal nanoclusters as highly active catalysts," Journal of Power Sources, vol. 168, no. 1, pp. 135-142, 2007.

[26] M. Rakap, E. E. Kalu, and S. Özkar, "Polymer-immobilized palladium supported on $\mathrm{TiO}_{2}\left(\mathrm{Pd}-\mathrm{PVB}-\mathrm{TiO}_{2}\right)$ as highly active and reusable catalyst for hydrogen generation from the hydrolysis of unstirred ammonia-borane solution," International Journal of Hydrogen Energy, vol. 36, pp. 1448-1455, 2011.

[27] G. P. Rachiero, U. B. Demirci, and P. Miele, "Facile synthesis by polyol method of a ruthenium catalyst supported on $\gamma-\mathrm{Al}_{2} \mathrm{O}_{3}$ for hydrolytic dehydrogenation of ammonia borane," Catalysis Today, vol. 170, no. 1, pp. 85-92, 2011.

[28] P. X. Xi, F. J. Chen, G. Q. Xie et al., "Surfactant free RGO/Pd nanocomposites as highly active heterogeneous catalysts for the hydrolytic dehydrogenation of ammonia borane for chemical hydrogen storage," Nanoscale, vol. 4, pp. 5597-5601, 2012.

[29] Q. L. Yao, W. M. Shi, G. Feng et al., "Ultrafine Ru nanoparticles embedded in $\mathrm{SiO}_{2}$ nanospheres: highly efficient catalysts for hydrolytic dehydrogenation of ammonia borane," Journal of Power Sources, vol. 257, pp. 293-299, 2014.

[30] J. M. Yan, X. B. Zhang, T. Akita, M. Haruta, and Q. Xu, "One-step seeding growth of magnetically recyclable Au@Co core-shell nanoparticles: highly efficient catalyst for hydrolytic dehydrogenation of ammonia borane," Journal of the American Chemical Society, vol. 132, pp. 5326-5327, 2010.

[31] X. Yang, F. Cheng, Z. Tao, and J. Chen, "Hydrolytic dehydrogenation of ammonia borane catalyzed by carbon supported Co core-Pt shell nanoparticles," Journal of Power Sources, vol. 196, no. 5, pp. 2785-2789, 2011.

[32] L. Yang, W. Luo, and G. E. Cheng, "Graphene-supported Ag-based core-shell nanoparticles for hydrogen generation in 
hydrolysis of ammonia borane and methylamine borane," ACS Applied Materials \& Interfaces, vol. 5, pp. 8231-8240, 2013.

[33] M. Wen, B. L. Sun, B. Zhou, Q. S. Wu, and J. Peng, "Controllable assembly of $\mathrm{Ag} / \mathrm{C} / \mathrm{Ni}$ magnetic nanocables and its low activation energy dehydrogenation catalysis," Journal of Materials Chemistry, vol. 22, pp. 11988-11993, 2012.

[34] G. P. Rachiero, U. B. Demirci, and P. Miele, "Bimetallic RuCo and $\mathrm{RuCu}$ catalysts supported on $\gamma-\mathrm{Al}_{2} \mathrm{O}_{3}$. A comparative study of their activity in hydrolysis of ammonia-borane," International Journal of Hydrogen Energy, vol. 36, no. 12, pp. 7051-7065, 2011.

[35] L. Yang, G. Cheng, J. Su, W. Luo, and X. Meng, "In situ synthesis of graphene supported Ag@CoNi core-shell nanoparticles as highly efficient catalysts for hydrogen generation from hydrolysis of ammonia borane and methylamine borane," Journal of Materials Chemistry A, vol. 1, pp. 10016-10023, 2013.

[36] L. S. Ott and R. G. Finke, "Transition-metal nanocluster stabilization for catalysis: a critical review of ranking methods and putative stabilizers," Coordination Chemistry Reviews, vol. 251, pp. 1075-1100, 2007.

[37] X. Huang, X. Y. Qi, F. Boey, and H. Zhang, "Graphene-based composites," Chemical Society Reviews, vol. 41, pp. 666-686, 2012.

[38] S. Garaj, W. Hubbard, A. Reina, J. Kong, D. Branton, and J. A. Golovchenko, "Graphene as a subnanometre trans-electrode membrane,” Nature, vol. 467, no. 7312, pp. 190-193, 2010.

[39] Z.-H. Lu, H.-L. Jiang, M. Yadav, K. Aranishi, and Q. Xu, "Synergistic catalysis of Au-Co@SiO ${ }_{2}$ nanospheres in hydrolytic dehydrogenation of ammonia borane for chemical hydrogen storage," Journal of Materials Chemistry, vol. 22, no. 11, pp. 50655071, 2012.

[40] D. Q. Wu, F. Zhang, H. W. Liang, and X. L. Feng, "Nanocomposites and macroscopic materials: assembly of chemically modified graphene sheets," Chemical Society Reviews, vol. 41, pp. 6160-6177, 2012.

[41] W. S. Hummers Jr. and R. E. Offeman, "Preparation of graphitic oxide," Journal of the American Chemical Society, vol. 80, no. 6, p. 1339, 1958.

[42] N. I. Kovtyukhova, P. J. Ollivier, B. R. Martin et al., "Layer-bylayer assembly of ultrathin composite films from micron-sized graphite oxide sheets and polycations," Chemistry of Materials, vol. 11, pp. 771-778, 1999.

[43] A. Roucoux, J. Schulz, and H. Patin, "Reduced transition metal colloids: a novel family of reusable catalysts?" Chemical Reviews, vol. 102, no. 10, pp. 3757-3778, 2002.

[44] D. Astruc, F. Lu, and J. R. Aranzaes, "Nanoparticles as recyclable catalysts: the frontier between homogeneous and heterogeneous catalysis," Angewandte Chemie International Edition, vol. 44, no. 48, pp. 7852-7872, 2005.

[45] P. Song, Y. Li, W. Li, B. He, J. Yang, and X. Li, "A highly efficient Co (0) catalyst derived from metal-organic framework for the hydrolysis of ammonia borane," International Journal of Hydrogen Energy, vol. 36, no. 17, pp. 10468-10473, 2011.

[46] K. W. Park, J. H. Choi, B. K. Kwon, S. Lee, and A. Y. E. Sung, "Chemical and electronic effects of $\mathrm{Ni}$ in $\mathrm{Pt} / \mathrm{Ni}$ and $\mathrm{Pt} / \mathrm{Ru} / \mathrm{Ni}$ alloy nanoparticles in methanol electrooxidation," Journal of Physical Chemistry B, vol. 106, pp. 1869-1877, 2002. 

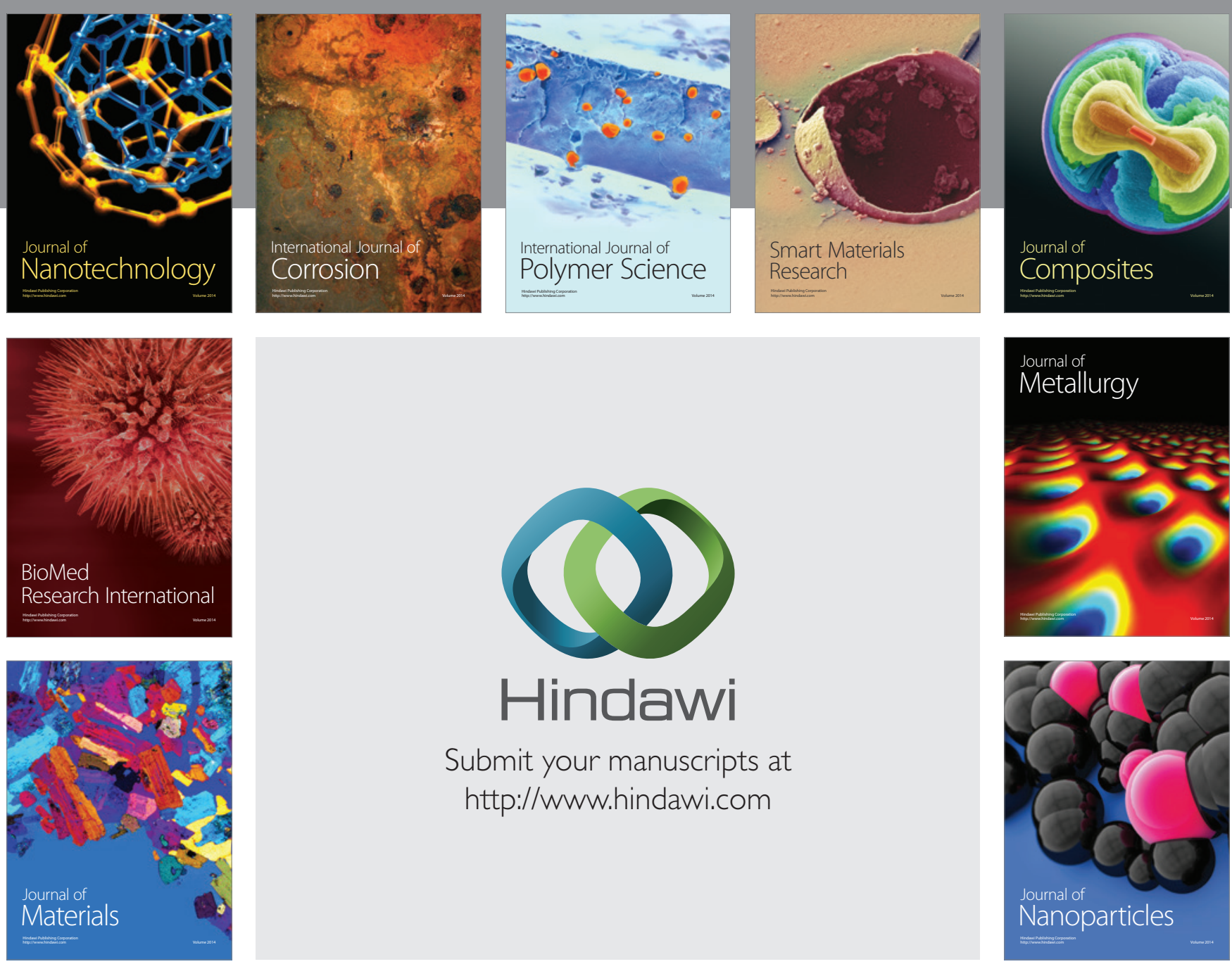

Submit your manuscripts at http://www.hindawi.com
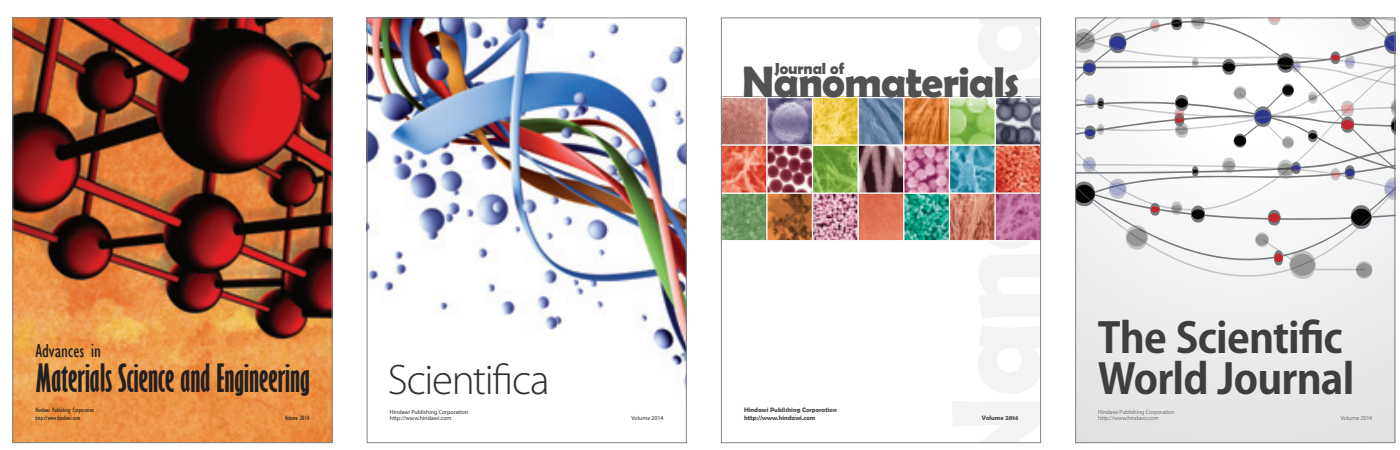

\section{The Scientific World Journal}
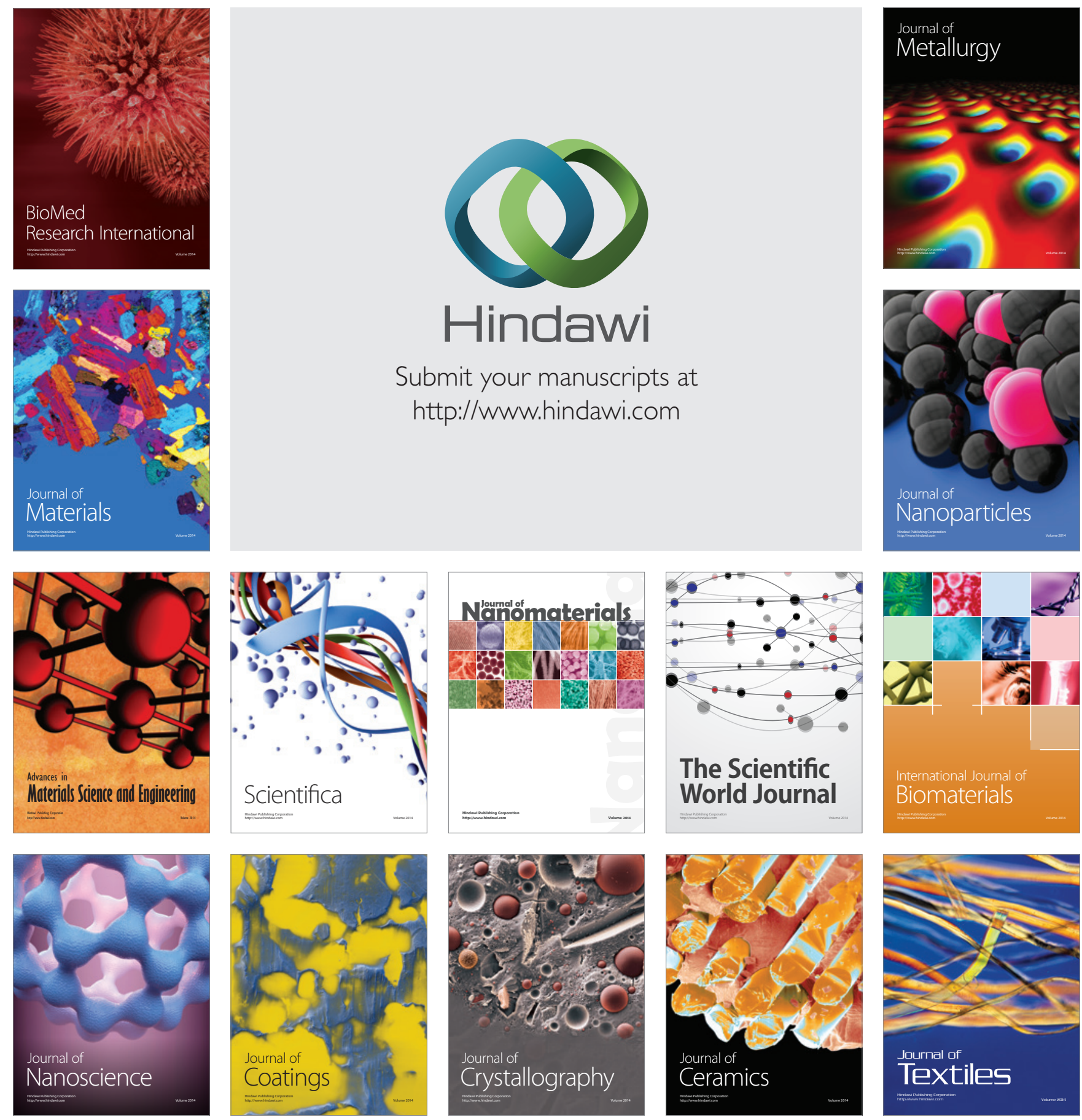